\title{
Impact of Partial Pressure of Oxygen in Blood Samples on the Performance of Systems for Self-Monitoring of Blood Glucose
}

\author{
Christina Schmid, PhD, Annette Baumstark, PhD, Stefan Pleus, MS, \\ Cornelia Haug, MD, Martina Tesar, and Guido Freckmann, MD
}

\begin{abstract}
Background: The partial pressure of oxygen $\left(\mathrm{pO}_{2}\right)$ in blood samples can affect glucose measurements with oxygen-sensitive systems. In this study, we assessed the influence of different $\mathrm{pO}_{2}$ levels on blood glucose (BG) measurements with five glucose oxidase (GOD) systems and one glucose dehydrogenase (GDH) system. All selected GOD systems were indicated by the manufacturers to be sensitive to increased oxygen content of the blood sample.

Materials and Methods: Venous blood samples of 16 subjects (eight women, eight men; mean age, 52 years; three with type 1 diabetes, four with type 2 diabetes, and nine without diabetes) were collected. Aliquots of each sample were adjusted to the following $\mathrm{pO}_{2}$ values: $\leq 45 \mathrm{~mm} \mathrm{Hg}$, approximately $70 \mathrm{~mm} \mathrm{Hg}$, and $\geq 150 \mathrm{~mm} \mathrm{Hg}$. For each system, five consecutive measurements on each sample were performed using the same test strip lot. Relative differences between the mean BG value at a $\mathrm{pO}_{2}$ level of approximately $70 \mathrm{~mm} \mathrm{Hg}$, which was considered to be similar to $\mathrm{pO}_{2}$ values in capillary blood samples, and the mean $\mathrm{BG}$ value at $\mathrm{pO}_{2}$ levels $\leq 45 \mathrm{~mm} \mathrm{Hg}$ and $\geq 150 \mathrm{~mm} \mathrm{Hg}$ were calculated.

Results: The GOD systems showed mean relative differences between $11.8 \%$ and $44.5 \%$ at $\mathrm{pO}_{2}$ values $\leq 45 \mathrm{~mm} \mathrm{Hg}$ and between $-14.6 \%$ and $-21.2 \%$ at $\mathrm{pO}_{2}$ values $\geq 150 \mathrm{~mm} \mathrm{Hg}$. For the GDH system, the mean relative differences were $-0.3 \%$ and $-0.2 \%$ at $\mathrm{pO}_{2}$ values $\leq 45 \mathrm{~mm} \mathrm{Hg}$ and $\geq 150 \mathrm{~mm} \mathrm{Hg}$, respectively.

Conclusions: The magnitude of the $\mathrm{pO}_{2}$ impact on $\mathrm{BG}$ measurements seems to vary among the tested oxygen-sensitive GOD systems. The $\mathrm{pO}_{2}$ range in which oxygen-sensitive systems operate well should be provided in the product information.
\end{abstract}

\section{Background}

Ystems for SElf-Monitoring of blood glucose (SMBG) $\checkmark$ use biosensors that facilitate the conversion of glucose in a reaction that generates a signal (e.g., a current) proportional to the glucose level in the blood sample. Usually the biosensor is located within a capillary chamber on the test strip as a thin, dry layer comprising a mixture of enzymes, mediators, and other chemical components that react specifically with glucose. ${ }^{1,2}$ The most commonly used enzymes in such biosensors are glucose oxidase (GOD) and glucose dehydrogenase (GDH).

Because oxygen is the physiological electron acceptor of GOD, systems that use a GOD enzyme reaction on test strips (hereafter denoted as GOD systems) are in principle prone to oxygen interferences (Fig. 1). ${ }^{3-5}$ To minimize the oxygen dependency of GOD systems, the biosensors usually contain a nonphysiological electron acceptor (mediator), such as ferrocene, ferricyanide, or a conducting organic salt (Fig. 1). ${ }^{3-5}$ The properties of the utilized mediator, for example, stability, kinetics, and ability to compete with oxygen, are an important aspect concerning the level of elimination of the GOD systems' oxygen dependency. ${ }^{4,5}$ However, detailed information concerning the components and electrochemical reaction of biosensors of currently available SMBG systems is limited. In contrast to GOD systems, those that use a GDH enzyme reaction on test strips (denoted hereafter as GDH systems) are-due to the nature of the chemistry usedoxygen insensitive. ${ }^{4,6-8}$

Previous investigations have shown that increases of the partial pressure of oxygen $\left(\mathrm{pO}_{2}\right)$ in blood samples result in considerable measurement bias of some oxygen-dependent GOD systems. ${ }^{7-11}$ Over- or underestimated blood glucose (BG) values of a given SMBG system can result in undetected hypo- or hyperglycemic events and may adversely affect therapeutic decisions.

In this study, we investigated the influence of different $\mathrm{pO}_{2}$ levels on BG measurements with five GOD systems and one GDH system. All selected GOD systems were indicated by the manufacturers to be sensitive to increased oxygen content of the blood sample.

Institut für Diabetes-Technologie Forschungs- und Entwicklungsgesellschaft mbH an der Universität Ulm, Ulm, Germany. 
A Basic enzyme reactions

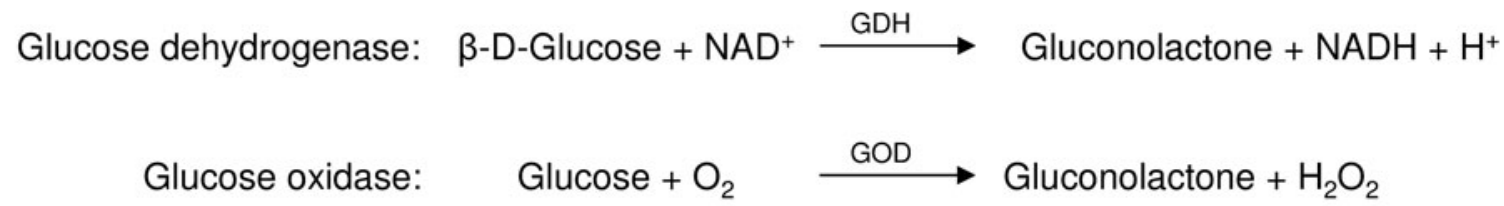

B Reactions on test strips
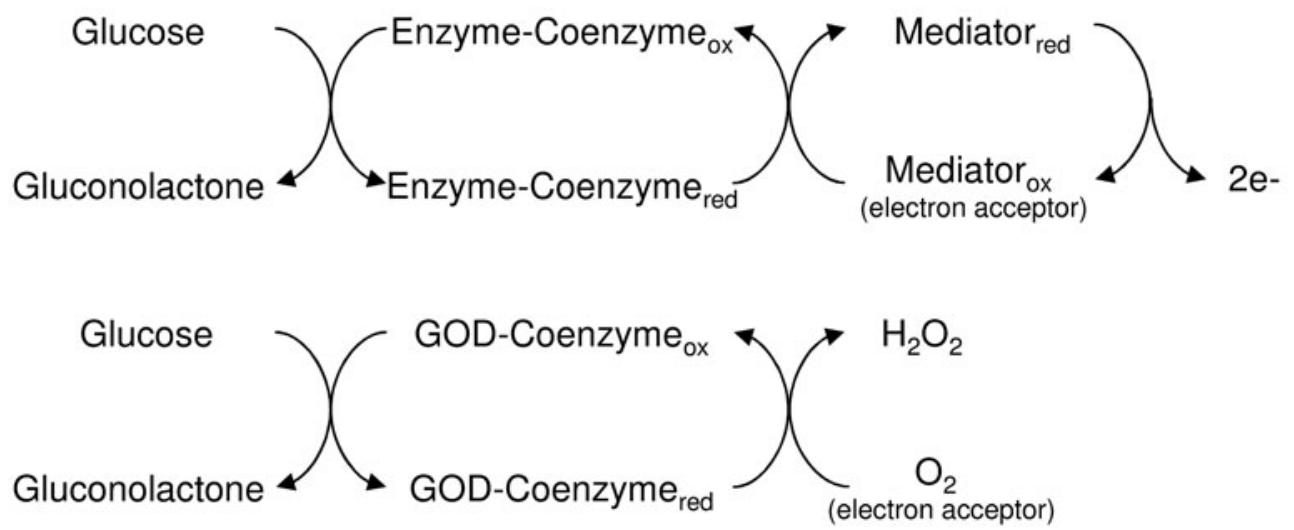

FIG. 1. (A) Basic enzyme reactions. (B) Reaction on test strips (modified from multiple sources ${ }^{1-4,7,6}$ ). In current selfmonitoring of blood glucose systems, the enzyme (glucose oxidase [GOD] or glucose dehydrogenase [GDH]) and its coenzyme catalyze the oxidation of glucose. A mediator is used as electron acceptor that transfers electrons from the enzymecoenzyme complex to the electrode (reaction 1). Because oxygen is the physiological electron acceptor for the GOD enzyme, it is possible that $\mathrm{O}_{2}$ competes with the mediator (reaction 2). In GOD-based self-monitoring of blood glucose systems, increased or decreased $\mathrm{O}_{2}$ concentrations may result in underestimated (overestimated) blood glucose concentrations. ox, oxidized; red, reduced.

\section{Materials and Methods}

This study was performed in December 2012 in compliance with the German Medical Devices Act at the Institut für Diabetes-Technologie Forschungs- und Entwicklungsgesellschaft $\mathrm{mbH}$ an der Universität Ulm, Ulm, Germany. The study protocol was approved by the responsible ethics committee, and the relevant authority was notified. Informed consent forms were signed by all subjects prior to the study commencing. Sixteen subjects were included in this evaluation (eight women, eight men; mean age, 52 years (range, 24-76 years): three with type 1 diabetes, four with type 2 diabetes, and nine subjects without diabetes. Because it was expected that having diabetes or not has no influence on the measurement quality of the systems investigated, subjects were selected independent from having diabetes or their diabetes type. The subjects' anamnesis and medication were reviewed by a physician and compared with interfering substances indicated in the manufacturers' labeling.

\section{BG monitoring systems}

In this study, five electrochemical GOD systems (systems 1-5) and one electrochemical GDH system (system 6) from six different manufacturers were evaluated. In the test strip package inserts for the GOD systems it is stated that these systems are intended for BG measurements on capillary blood and, additionally, that measurement results can be affected by high blood oxygen concentrations or in patients receiving oxygen therapy.

All SMBG systems studied were purchased from pharmacies. The systems were stored, used, and maintained in compliance with the manufacturers' instructions. In addition, control measurements were performed daily, as indicated by the manufacturers, prior to the experimental procedure and for each test strip vial.

\section{Sample preparation and measurement procedure}

In this study, which required a large blood volume, venous blood samples were adjusted to different $\mathrm{pO}_{2}$ levels in order to assess the influence of the different $\mathrm{pO}_{2}$ values on $\mathrm{BG}$ measurement results.

Test procedures were performed by trained personnel in a laboratory setting with controlled room temperature (20$23^{\circ} \mathrm{C}$ ) and humidity (31-44\%). A venous blood sample from each of the 16 subjects was collected in lithium heparin tubes. The hematocrit value of the blood sample was determined in duplicate by using heparinized capillaries in order to ensure a hematocrit value within the range indicated in the manufacturers' labeling. For this purpose, capillary tubes were centrifuged, and the hematocrit value was determined using an alignment chart. Hematocrit values among the 16 subjects ranged between $38 \%$ and $54.5 \%$.

The $\mathrm{pO}_{2}$ values of the samples were analyzed by using a blood gas analyzer (OPTI ${ }^{\mathrm{TM}}$ CCA-TS analyzer; OPTI Medical 
Systems, Inc., Roswell, GA). For the preparation of test samples with three different $\mathrm{pO}_{2}$ levels, three aliquots of the venous blood sample were collected in one syringe each (approximately $2.5 \mathrm{~mL}$ ). Samples with the following $\mathrm{pO}_{2}$ levels were prepared: approximately $70 \mathrm{~mm} \mathrm{Hg}$, which was considered to be similar to $\mathrm{pO}_{2}$ values in capillary blood samples ${ }^{12,13}$; $\leq 45 \mathrm{~mm} \mathrm{Hg}$ (further also referred to as "low"); and $\geq 150 \mathrm{~mm} \mathrm{Hg}$ (further also referred to as "high"). Because the initial $\mathrm{pO}_{2}$ values of the venous blood samples, which were determined immediately after sample collection, ranged between $26 \mathrm{~mm} \mathrm{Hg}$ and $40 \mathrm{~mm} \mathrm{Hg}$, $\mathrm{pO}_{2}$ adjustment was not required for samples designated for $\mathrm{pO}_{2}$ values $\leq 45 \mathrm{~mm} \mathrm{Hg}$. The syringe with the sample designated for $\mathrm{pO}_{2}$ values $\leq 45 \mathrm{~mm} \mathrm{Hg}$ was deaerated, sealed airtight, and placed on a rotating mixer for sample incubation until the measurement procedure with the BG systems was performed. To achieve blood samples with $\mathrm{pO}_{2}$ values of approximately $70 \mathrm{~mm} \mathrm{Hg}$ and $\geq 150 \mathrm{~mm} \mathrm{Hg}$, a volume of $1-3 \mathrm{~mL}$ of air was added to the samples in the syringe before being airtight-sealed and incubated on a rotating mixer. During incubation, the $\mathrm{pO}_{2}$ values of all samples were checked repeatedly. For samples designated for approximately $70 \mathrm{~mm} \mathrm{Hg}$ and $\geq 150 \mathrm{~mm} \mathrm{Hg}$, the syringe was deaerated as soon as the desired $\mathrm{pO}_{2}$ value was reached in order to prevent any further $\mathrm{pO}_{2}$ increase.

The glucose measurement procedure with all SMBG systems was performed immediately after the sample had reached the designated $\mathrm{pO}_{2}$ value. The glucose level in each sample was measured with all six test systems. For each system, five consecutive measurements on a given blood sample were performed using the same test strip lot. In order to measure a blood sample as quickly as possible (to ensure nearly constant $\mathrm{pO}_{2}$ values), five different meters were used for each system. Before and after the glucose measurements with the SMBG systems, samples for measurements with the laboratory glucose analyzer were collected, hemolyzed, deproteinated (in test tubes containing perchloric acid), and centrifuged. The supernatants were transferred to fresh tubes, stored at $-20^{\circ} \mathrm{C}$, and measured using a hexokinase method (cobas $^{\circledR} 6000$ c501; Roche Diagnostics GmbH, Mannheim, Germany). BG measurement results with this laboratory method ranged between 82 and $206 \mathrm{mg} / \mathrm{dL}$.
In addition, the $\mathrm{pO}_{2}$ of the blood samples was also determined immediately before and after the glucose measurements with the SMBG systems in order to ensure nearly constant $\mathrm{pO}_{2}$ values of a sample during the measurement series. The 16 samples could be adjusted to the following mean $\mathrm{pO}_{2}$ values:

- samples designated to $\mathrm{pO}_{2}$ values approximately $70 \mathrm{~mm} \mathrm{Hg:} 73.5 \mathrm{~mm} \mathrm{Hg}$, ranging from 69 to $81 \mathrm{~mm} \mathrm{Hg}$

- samples designated to $\mathrm{pO}_{2}$ values $\leq 45 \mathrm{~mm} \mathrm{Hg}$ : $32.6 \mathrm{~mm} \mathrm{Hg}$, ranging from 27 to $41 \mathrm{~mm} \mathrm{Hg}$

- samples designated to $\mathrm{pO}_{2}$ values $\geq 150 \mathrm{~mm} \mathrm{Hg}$ : $165.5 \mathrm{~mm} \mathrm{Hg}$, ranging from 153 to $184 \mathrm{~mm} \mathrm{Hg}$

The maximal $\mathrm{pO}_{2}$ change during the measurement procedure was $<6 \%$, which we considered to be sufficiently stable.

\section{Data analysis}

Data management and evaluation were performed at the study site. Assessment of $\mathrm{pO}_{2}$ effects on the systems' measurements results was performed with descriptive statistics.

For each of the 16 samples, normalized relative differences between the mean BG value (five consecutive measurements per sample) of a system at "high" or "low" $\mathrm{pO}_{2}$ values and the mean BG value of that system at a $\mathrm{pO}_{2}$ value of approximately $70 \mathrm{~mm} \mathrm{Hg}$ were calculated. Changes in laboratory method results were also accounted for:

$$
d_{\text {norm }}=\frac{S_{n}-L_{n}+L_{70}-S_{70}}{S_{70}} \times 100(\text { in } \%)
$$

where $S_{n}$ is the mean BG value for a specific SMBG system at $\mathrm{pO}_{2}$ n ("low"; approximately $70 \mathrm{~mm} \mathrm{Hg}$; "high"), $L_{n}$ is the mean laboratory method result at $\mathrm{pO}_{2} n$ ("low"; approximately $70 \mathrm{~mm} \mathrm{Hg}$; "high"), $L_{70}$ is the mean laboratory method result at $\mathrm{pO}_{2}$ approximately $70 \mathrm{~mm} \mathrm{Hg}, S_{70}$ is the mean BG value for a specific SMBG system at $\mathrm{pO}_{2}$ approximately $70 \mathrm{~mm} \mathrm{Hg}$, and $d_{\text {norm }}$ is the normalized relative difference.

By applying this equation, the normalized relative difference at $\mathrm{pO}_{2}$ value approximately $70 \mathrm{~mm} \mathrm{Hg}$ was set to 0 . This was done because all tested systems were intended for use with capillary blood samples, and $\mathrm{pO}_{2}$ values approximately $70 \mathrm{~mm} \mathrm{Hg}$ (ranging from 69 to $81 \mathrm{~mm} \mathrm{Hg}$ in this study) were

Table 1. Mean Normalized Relative Differences of the Glucose Oxidase Systems 1-5 and the Glucose Dehydrogenase System 6 at Partial Pressure of Oxygen Values $\leq 45$ mM Hg and $\geq 150$ mm Hg

\begin{tabular}{|c|c|c|c|c|c|c|}
\hline & \multicolumn{5}{|c|}{ GOD systems } & \multirow[b]{2}{*}{ GDH system (system 6, } \\
\hline & System 1 & System 2 & System 3 & System 4 & System 5 & \\
\hline \multicolumn{7}{|c|}{ Relative differences $\mathrm{pO}_{2} \leq 45 \mathrm{~mm} \mathrm{Hg}$} \\
\hline Mean & $30.2 \%$ & $11.8 \%$ & $44.5 \%$ & $24.9 \%$ & $29.7 \%$ & $-0.3 \%$ \\
\hline $\mathrm{SD}$ & $9.2 \%$ & $5.0 \%$ & $16.2 \%$ & $6.6 \%$ & $10.1 \%$ & $2.4 \%$ \\
\hline Minimum & $12.6 \%$ & $5.5 \%$ & $20.9 \%$ & $16.0 \%$ & $15.2 \%$ & $-0.1 \%$ \\
\hline Maximum & $43.4 \%$ & $26.1 \%$ & $71.5 \%$ & $36.2 \%$ & $50.2 \%$ & $-5.6 \%$ \\
\hline \multicolumn{7}{|c|}{ Relative differences $\mathrm{pO}_{2} \geq 150 \mathrm{~mm} \mathrm{Hg}$} \\
\hline Mean & $-20.2 \%$ & $-14.6 \%$ & $-21.2 \%$ & $-17.3 \%$ & $-15.8 \%$ & $-0.2 \%$ \\
\hline SD & $5.8 \%$ & $3.8 \%$ & $5.2 \%$ & $4.6 \%$ & $6.3 \%$ & $1.5 \%$ \\
\hline Minimum & $-11.5 \%$ & $-8.1 \%$ & $-13.0 \%$ & $-10.2 \%$ & $-7.2 \%$ & $-0.1 \%$ \\
\hline Maximum & $-33.0 \%$ & $-21.5 \%$ & $-30.4 \%$ & $-26.5 \%$ & $-27.1 \%$ & $-3.3 \%$ \\
\hline
\end{tabular}

There were 16 samples each, five measurements per sample.

$\mathrm{GDH}$, glucose dehydrogenase; GOD, glucose oxidase; $\mathrm{pO}_{2}$, partial pressure of oxygen. 
considered to be similar to $\mathrm{pO}_{2}$ values in fresh capillary blood samples. $^{12,13}$

For each $\mathrm{BG}$ system and each $\mathrm{pO}_{2}$ level, the normalized relative difference of each of the 16 samples (five measurements per sample) was calculated. In addition, the mean value over all 16 normalized relative differences was calculated.

\section{Results}

Among the GOD systems 1-5, the mean normalized relative differences at "low" $\mathrm{pO}_{2}$ values were between $11.8 \%$ and $44.5 \%$ (Table 1 ); the highest variation of mean normalized relative differences was found in system 3, ranging from $20.9 \%$ to $71.5 \%$ (Table 1 and Figs. 2 and 3). Regarding $\mathrm{pO}_{2}$ values $\geq 150 \mathrm{~mm} \mathrm{Hg}$, mean normalized relative differences were between $-14.6 \%$ and $-21.2 \%$; the highest variation was found in system 1 , with mean normalized relative differences ranging from $-11.5 \%$ to $-33.0 \%$ (Table 1 and Figs. 2 and 3 ). For the GDH system (system 6), the mean relative differences were $-0.3 \%$ at $\mathrm{pO}_{2}$ values $\leq 45 \mathrm{~mm} \mathrm{Hg}$ and $-0.2 \%$ at $\mathrm{pO}_{2}$ values $\geq 150 \mathrm{~mm} \mathrm{Hg}$.

\section{Discussion}

In this study, the influence of different blood $\mathrm{pO}_{2}$ levels on BG measurement results was investigated in five GOD systems and one GDH system. All investigated GOD systems were affected by "high" and "low" $\mathrm{pO}_{2}$ values of the blood sample. Because oxygen is not involved in the electrochemical reaction catalyzed by GDH, an influence of the samples' $\mathrm{pO}_{2}$ values on measurement results was not expected, and actually the GDH system was not affected by the $\mathrm{pO}_{2}$ value of the sample.

The $\mathrm{pO}_{2}$ level of approximately $70 \mathrm{mmHg}$ was considered to be similar to $\mathrm{pO}_{2}$ values in capillary blood samples. ${ }^{12,13}$ Low $\mathrm{pO}_{2}$ values can be found in patients with respiratory diseases or at high altitude (e.g., hiking, mountaineering, during air travel). ${ }^{14-19}$ Increased $\mathrm{pO}_{2}$ values can occur in patients requiring artificial respiration. $9,11,20$

In this study, at "high" $\mathrm{pO}_{2}$ values the GOD systems showed a negative bias for the measurement results compared with those at $\mathrm{pO}_{2}$ values approximately $70 \mathrm{~mm} \mathrm{Hg}$. This is in line with several other studies reporting that some GOD systems underestimate BG values when measurements were performed on blood samples with increased $\mathrm{pO}_{2}$ values. ${ }^{8,9,11,21}$ In such studies, measurements on adjusted venous blood samples with $\mathrm{pO}_{2}$ values $>100 \mathrm{~mm} \mathrm{Hg}$ or in critically ill patients/patients undergoing surgery with increased arterial $\mathrm{pO}_{2}$ values up to approximately $600 \mathrm{~mm} \mathrm{Hg}$ resulted in a negative bias. Probably, the competition between dissolved oxygen in the blood sample and the electron acceptor on the biosensor of test strips leads to a diminished chemical reaction when the blood samples' $\mathrm{pO}_{2}$ value is increased. ${ }^{2,4}$ Therefore, in patients with increased $\mathrm{pO}_{2}$ values, the use of oxygendependent SMBG systems is not recommended.,

Information concerning the influence and clinical impact of decreased $\mathrm{pO}_{2}$ values on oxygen-sensitive GOD systems is limited. Mahoney et al. ${ }^{22}$ argued that low $\mathrm{pO}_{2}$ values of venous blood samples can result in a positive bias of the measurement results with oxygen-sensitive systems intended for $\mathrm{pO}_{2}$ values in capillary blood samples. Previous studies investigated the influence of high altitude, which is also characterized by decreased $\mathrm{pO}_{2}$ values, on $\mathrm{BG}$ measurement results. However, results of these studies are conflicting and difficult to interpret; most of the available data were either obtained with older-generation systems, or the evaluation procedures were not described in detail. ${ }^{23-27}$ In our study, a considerable influence of "low" $\mathrm{pO}_{2}$ values on the investigated GOD systems was found to give a positive bias on the measurement results compared with those at $\mathrm{pO}_{2}$ values approximately $70 \mathrm{~mm} \mathrm{Hg}$.

Low $\mathrm{pO}_{2}$ values can occur in daily life conditions of people with diabetes, for example, in patients with respiratory diseases or during activities at higher altitudes or during air travel. During long-distance flights, conditions in commercial aircraft cabins correspond to an altitude of approximately $2,400 \mathrm{~m}$ for many hours. ${ }^{18,19}$ The decreased ambient $\mathrm{pO}_{2}$ at such altitude can lead to decreased arterial $\mathrm{pO}_{2}$ values of about $55-65 \mathrm{~mm} \mathrm{Hg} .{ }^{17-19}$ In such conditions BG measurements with oxygen-sensitive systems might bear a risk that hypoglycemic events might not be detected in time.

This evaluation was performed in a controlled laboratory setting, in which other interfering factors were reduced to a minimum. However, the study has limitations that should be considered when interpreting the results. The five GOD systems are labeled for use with capillary blood only. According to clause 6.4 of the International Organization for Standardization (ISO) 15197:2013 standard, ${ }^{28}$ in which the preferred sample material for interference testing is venous blood, venous blood was adjusted to different $\mathrm{pO}_{2}$ levels in order to evaluate the impact of the blood samples' $\mathrm{pO}_{2}$ on BG measurement results. The results indicate that different blood oxygen contents affect BG measurements with oxygensensitive GOD systems.

Having diabetes or not was not expected to influence this study's results, and thus subjects were selected independent from having diabetes or not. However, verification of this assumption was not performed on the study data as the number of subjects did not allow for proper subgroup analyses.

All GOD systems tested in this study were indicated by the manufacturers to be potentially affected by increased oxygen concentrations of the blood sample or in patients who are receiving oxygen therapy; hence, a dependence of the samples' $\mathrm{pO}_{2}$ on measurement results was expected. However, the results of this study indicate that the extent of the $\mathrm{pO}_{2}$ effects varies among these systems. One main reason that determines the occurrence and extent of $\mathrm{pO}_{2}$ effects is the electrochemical composition of the biosensor. Some manufacturers might have designed the GOD enzyme reaction of their system to be less or even not affected by oxygen. However, for most oxygen-sensitive labeled BG monitoring systems, detailed information concerning the $\mathrm{pO}_{2}$ limits of the system is not provided. In particular, information about a possible interference associated with conditions of decreased oxygen content in the blood sample that could prevent the timely detection of hypoglycemia is missing.

Recently, the $\mathrm{ISO}^{28}$ published a revision of the standard EN ISO 15197:2003, the ISO 15197:2013, in which requirements for SMBG systems are specified. In this revision, it is prescribed that interference effects shall be described in the instructions for use if the average difference between the test sample and the control sample exceeds $10 \mathrm{mg} / \mathrm{dL}(10 \%)$ for glucose concentrations $<100 \mathrm{mg} / \mathrm{dL}(\geq 100 \mathrm{mg} / \mathrm{dL})$. In addition, it is claimed that the conditions required to obtain accurate 


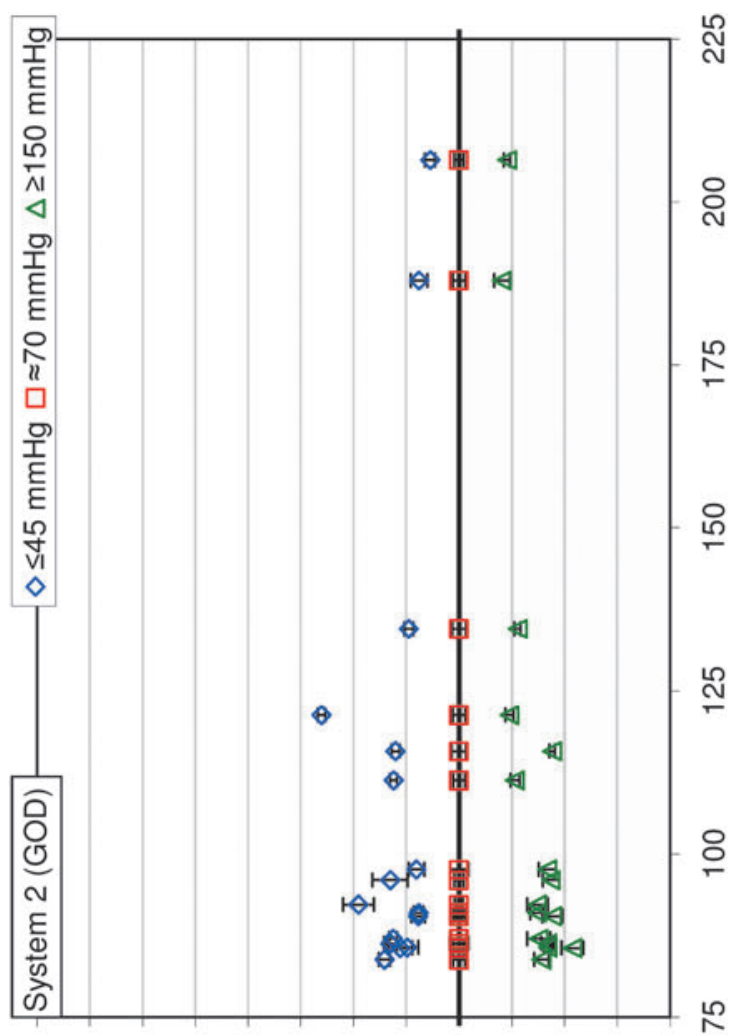

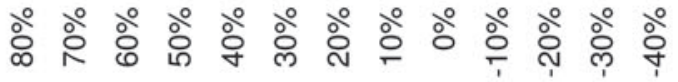

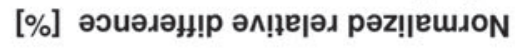

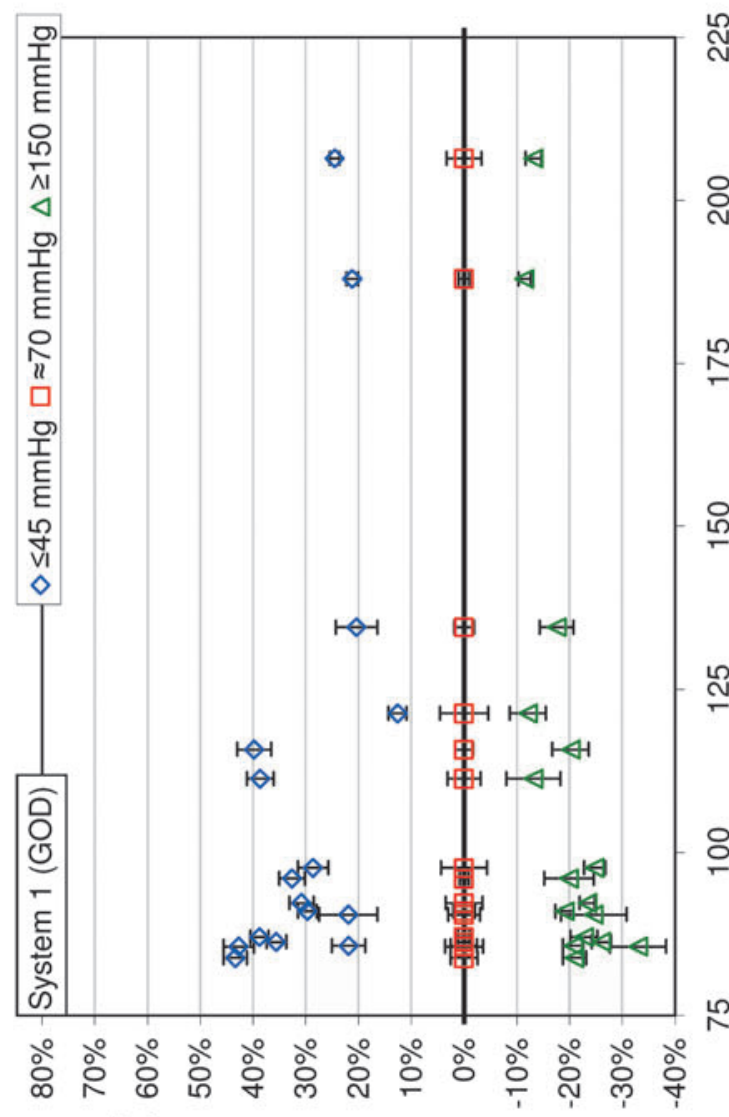

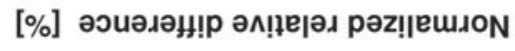

$\stackrel{2}{\circ}$

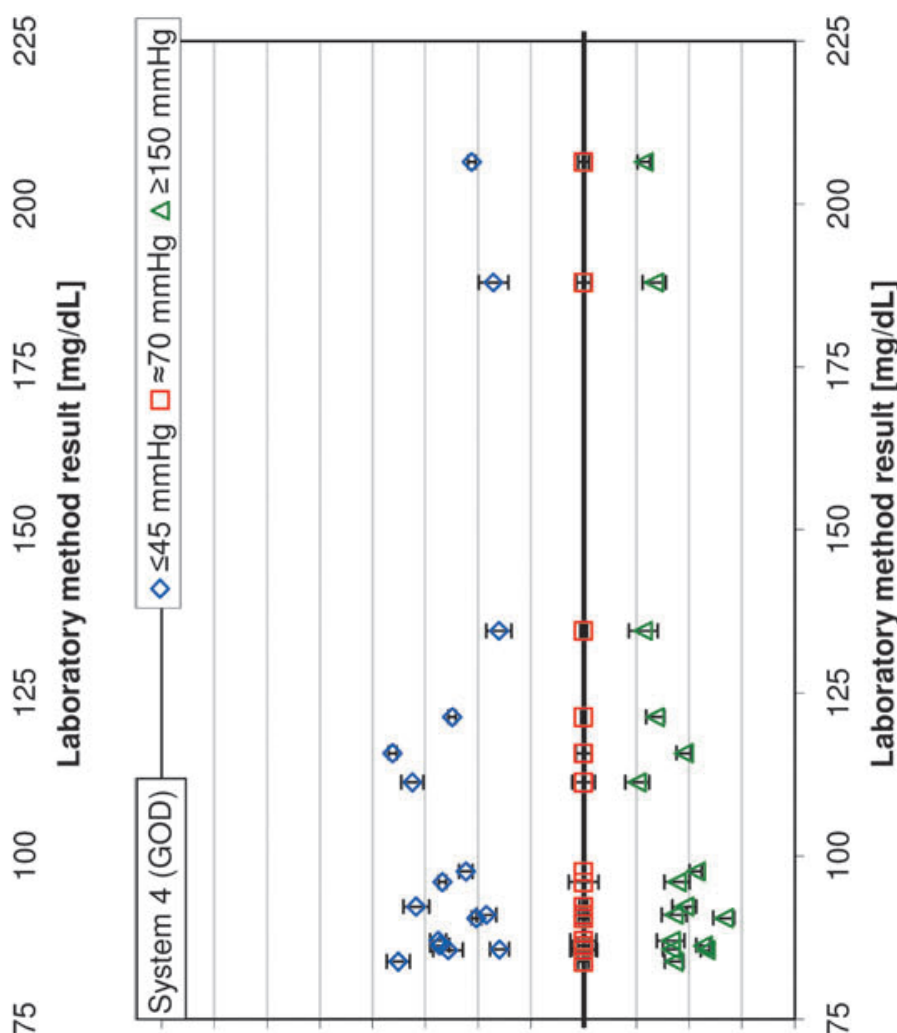

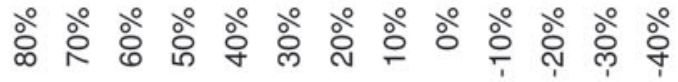

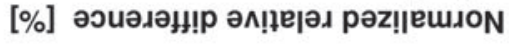
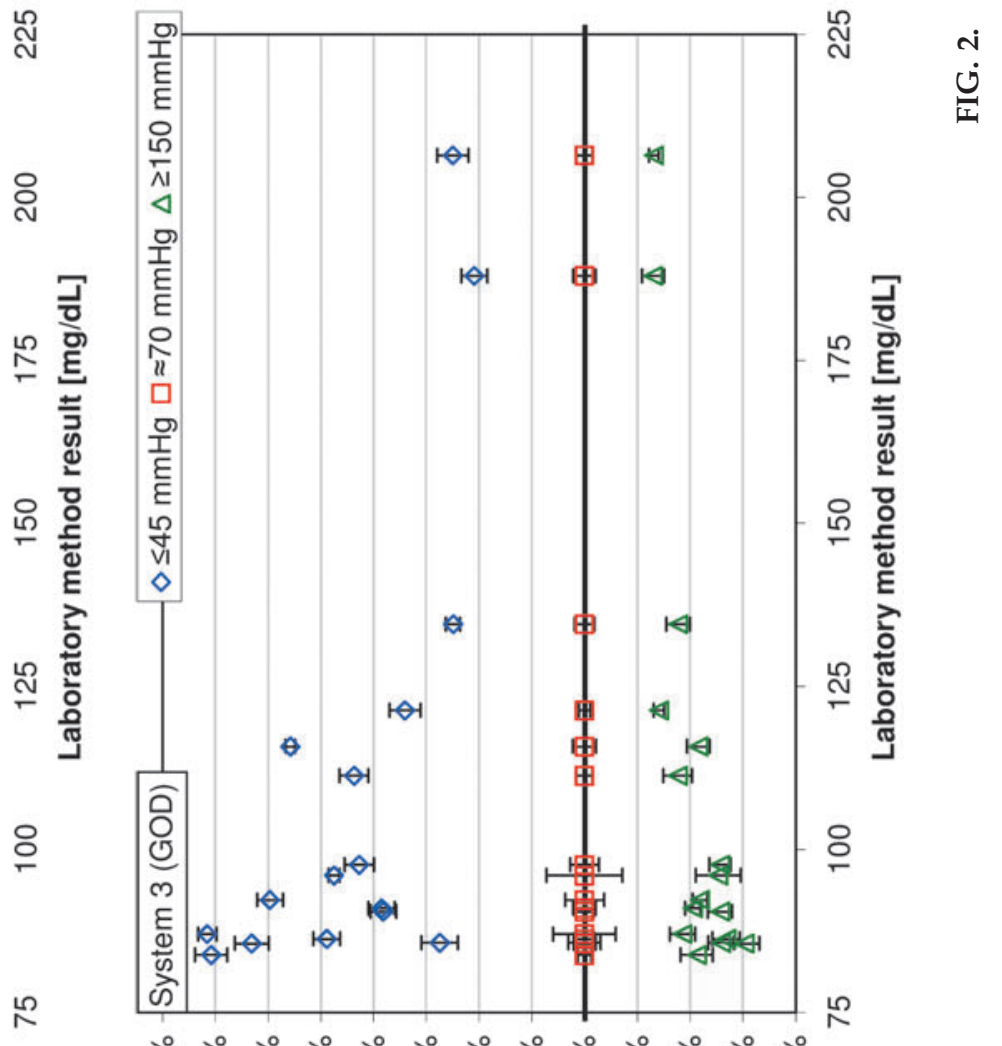

ㅇํ

공

$\stackrel{ }{\circ}$

은

논

음

$\stackrel{2}{\circ}$ 


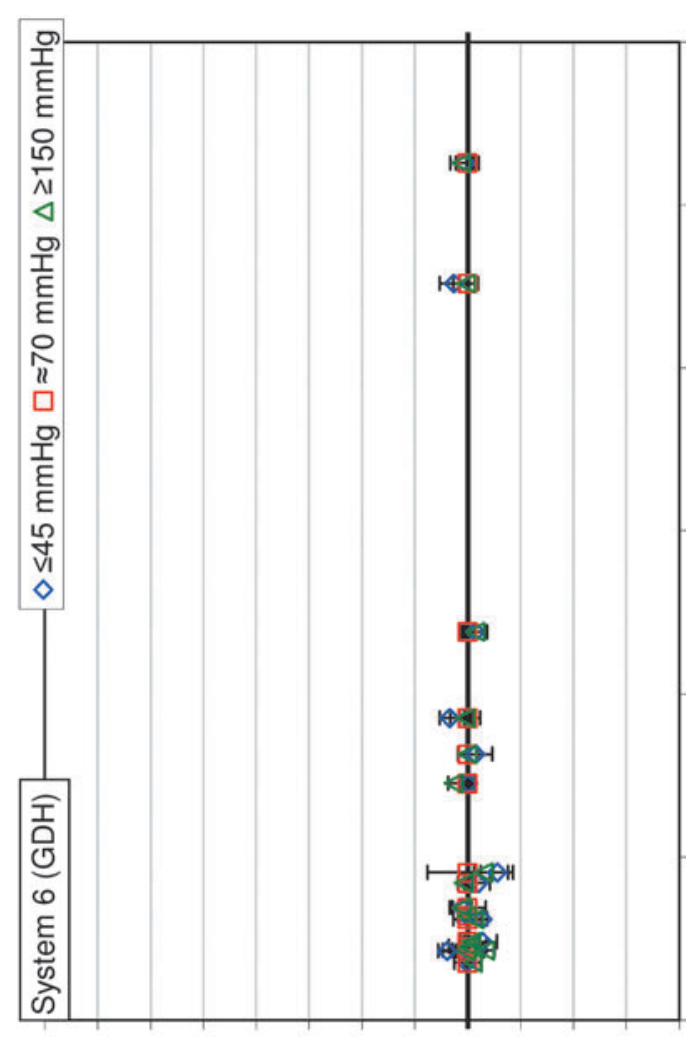

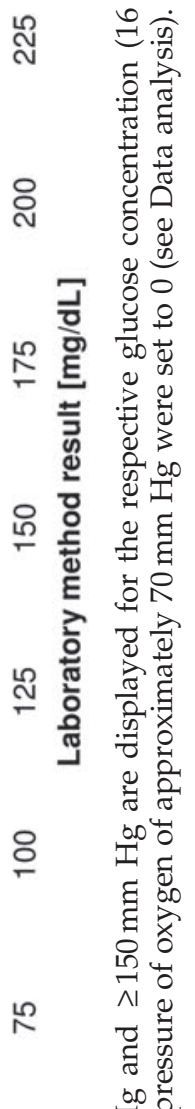

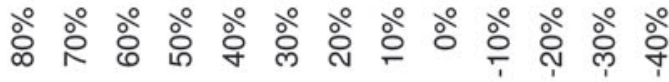

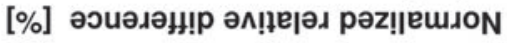

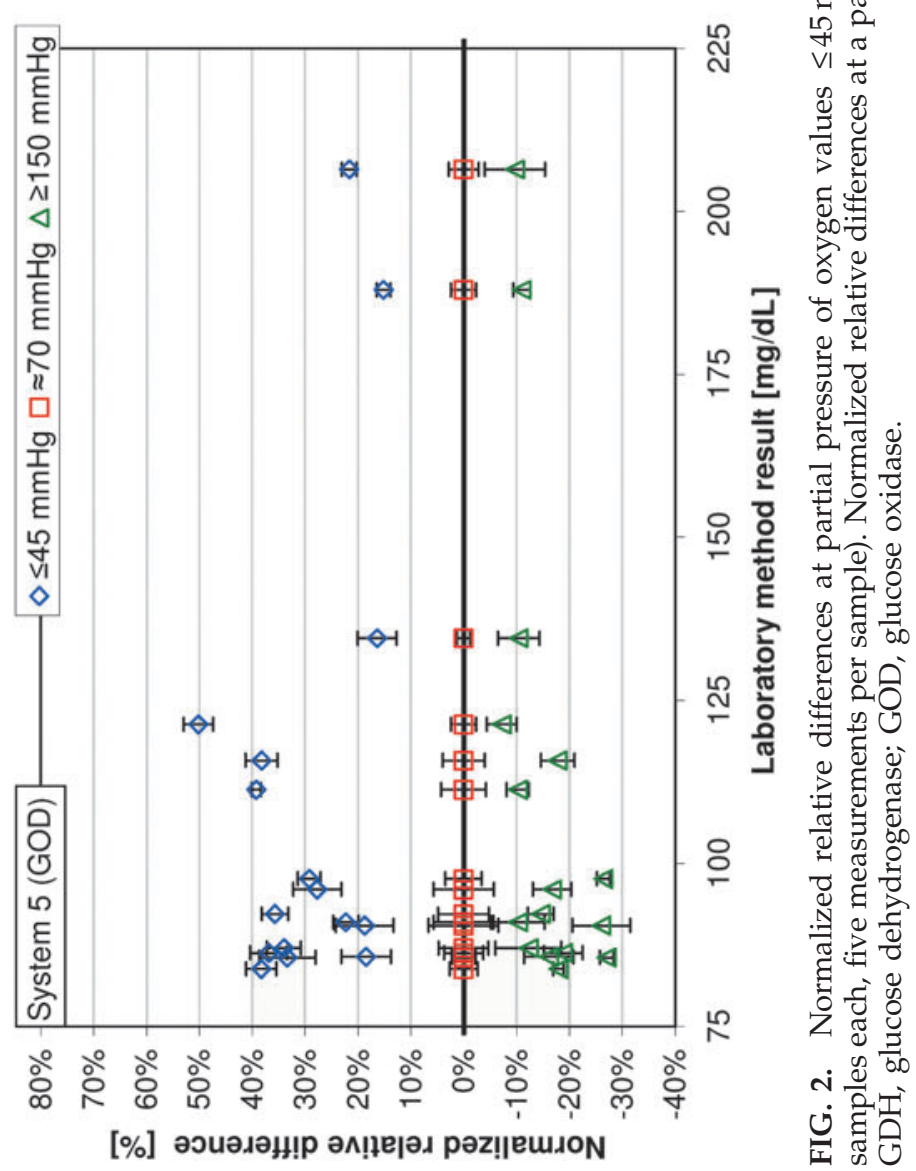




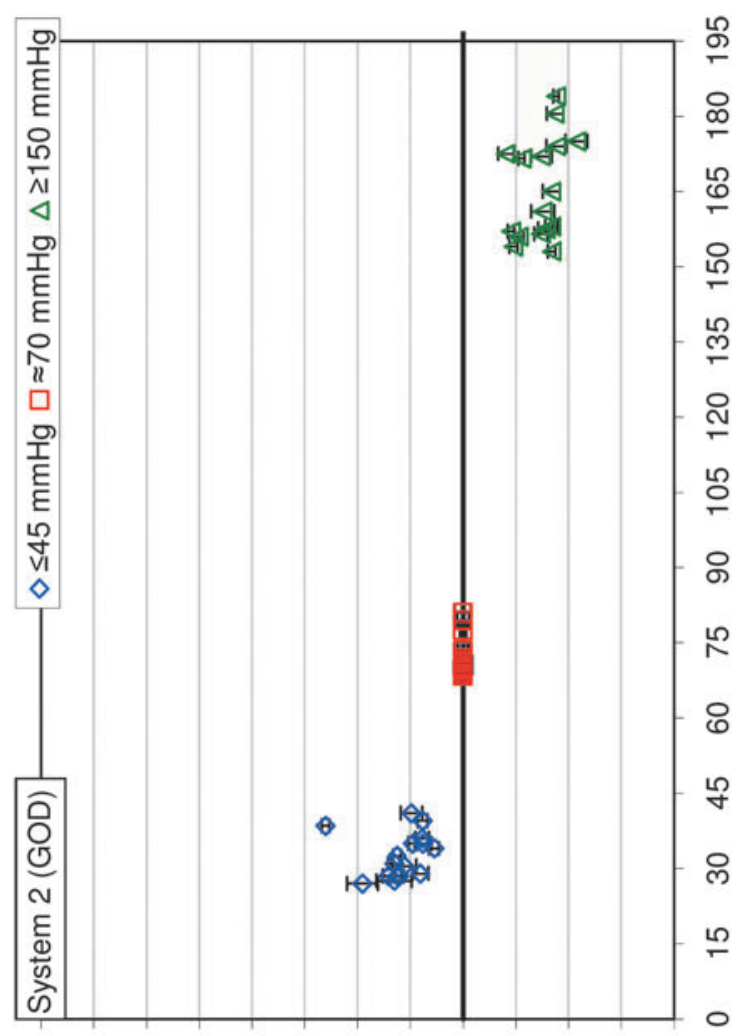

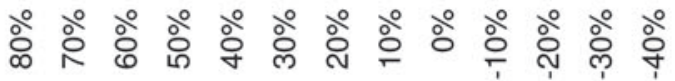

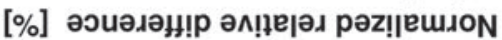

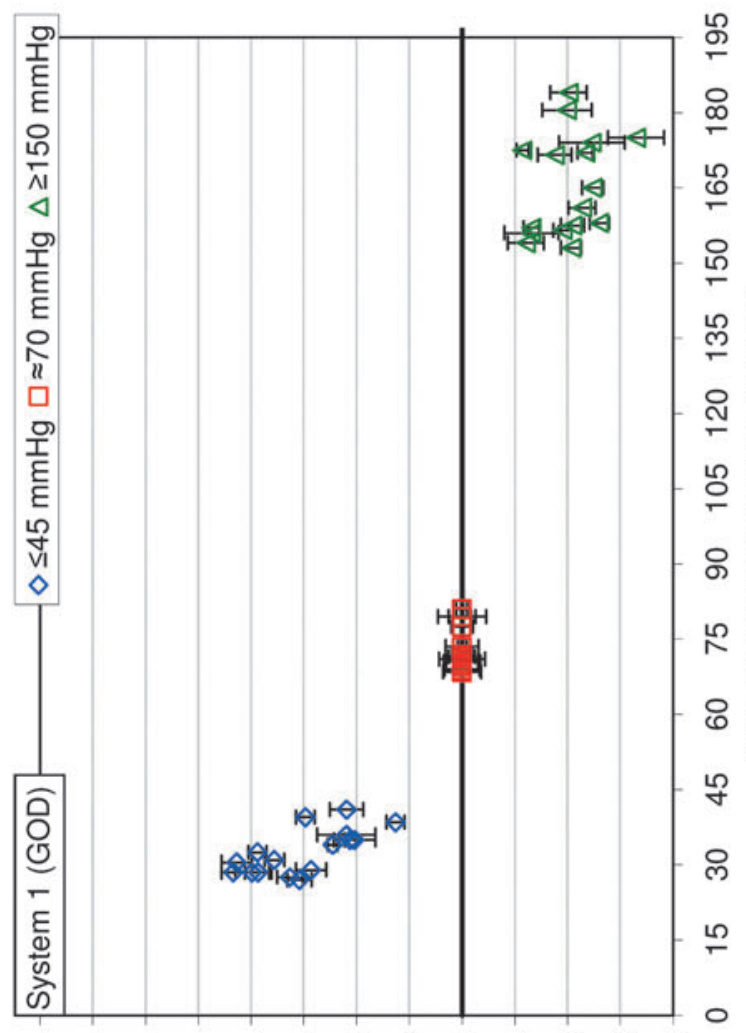

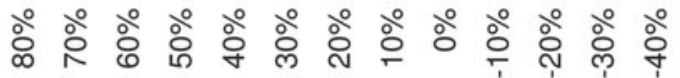

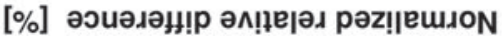

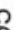
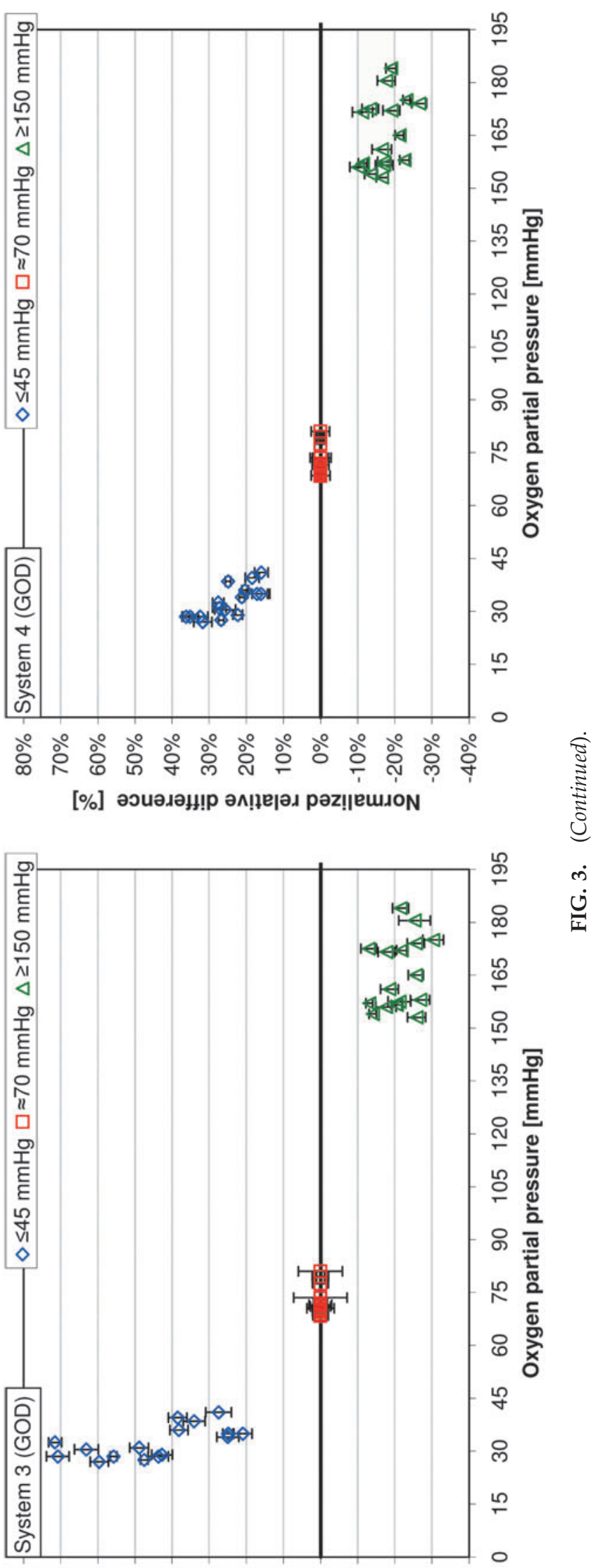

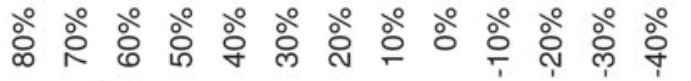

[\%] әэиәдән!р әм!ฺе|әд рәz!|ешגоN 


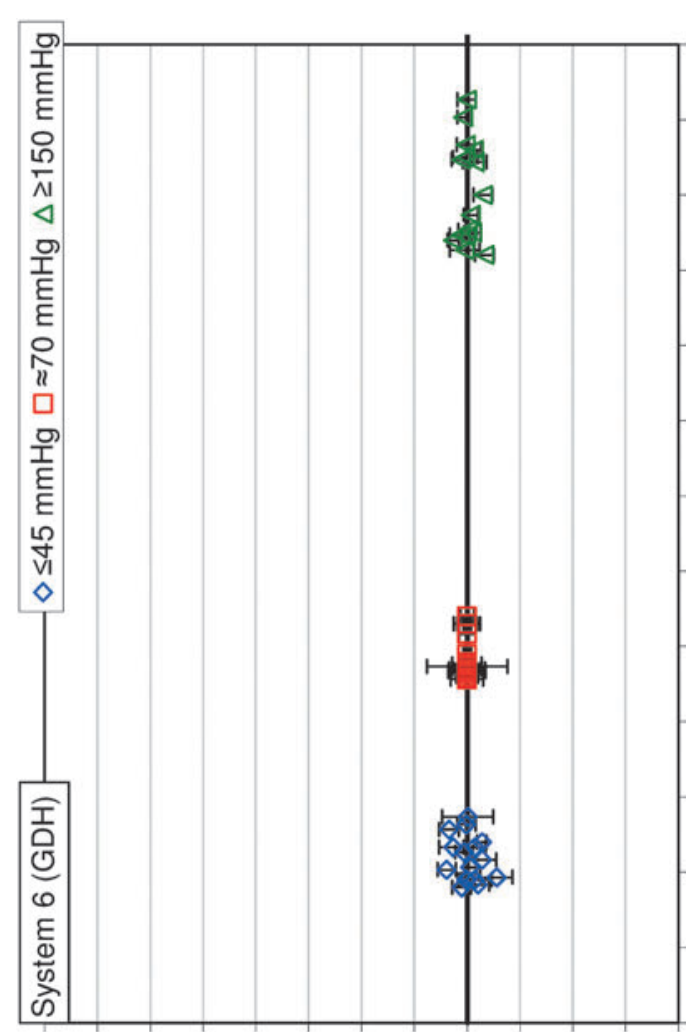

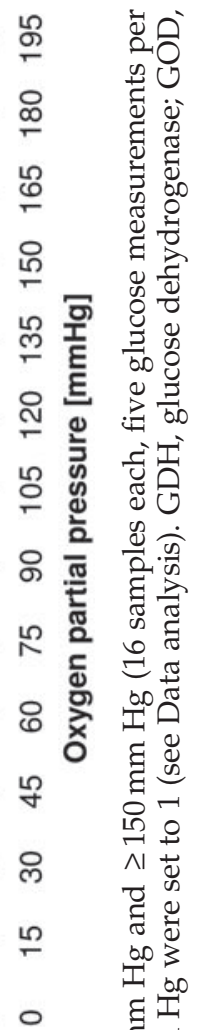

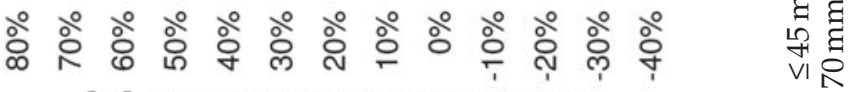

[\%] әэนәдән!р әк!ฺє|әג рәz!|ешлоN

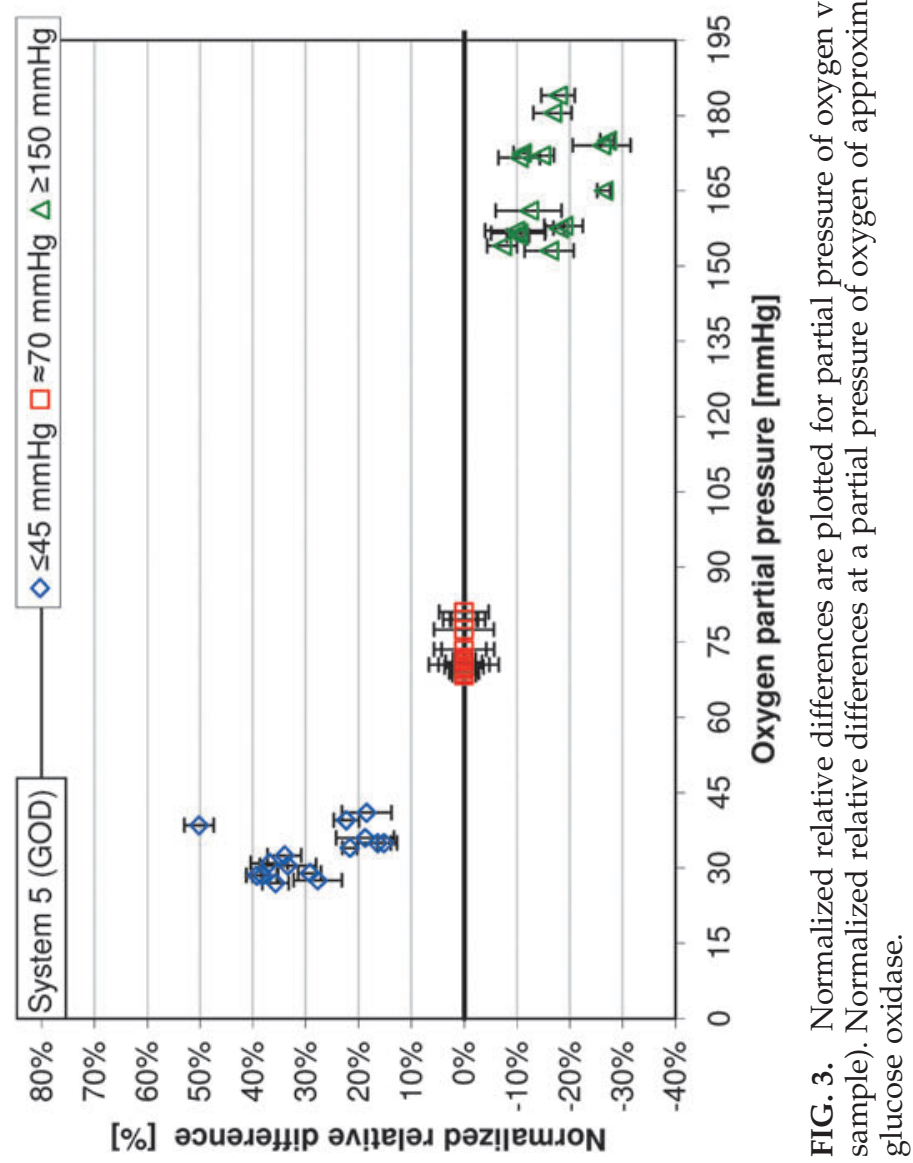


measured values shall be specified if the system is affected by environmental factors, such as oxygen.

In this context it should be mentioned that other clinically relevant conditions and factors (e.g., temperature, hematocrit, interfering drugs [e.g., acetaminophen, salicylates]) can also have a profound influence on BG measurements. A detailed description of all interfering substances and relevant conditions would enable a suitable and informed decision when choosing SMBG systems for a specific setting or a specific group of patients.

\section{Conclusions}

The magnitude of the $\mathrm{pO}_{2}$ effects on $\mathrm{BG}$ measurement results seems to vary among oxygen-sensitive SMBG systems, particularly at decreased $\mathrm{pO}_{2}$ values. To ensure an adequate use of oxygen-sensitive systems in daily life conditions of patients with diabetes, the $\mathrm{pO}_{2}$ range in which the systems operate well should be investigated further and should be provided in the product information.

\section{Acknowledgments}

This study was funded by a grant from Roche Diagnostics $\mathrm{GmbH}$, Mannheim, Germany. We would like to thank Lutz Heinemann, Volker Lodwig, Peter Müller, Joachim Hönes, and Andrew Hattemer for their valuable input.

\section{Author Disclosure Statement}

All authors are employees of the Institut für DiabetesTechnologie Forschungs- und Entwicklungsgesellschaft $\mathrm{mbH}$ an der Universität Ulm (IDT), Ulm, Germany. G.F. is general manager of the IDT, which carries out studies evaluating BG meters and medical devices for diabetes therapy on behalf of various companies. G.F./IDT have received speakers' honoraria or consulting fees from Abbott, Bayer, Menarini Diagnostics, Roche Diagnostics, Sanofi, and Ypsomed.

\section{References}

1. Vashist SK, Zheng D, Al-Rubeaan K, Luong JH, Sheu FS: Technology behind commercial devices for blood glucose monitoring in diabetes management: a review. Anal Chim Acta 2011;703:124-136.

2. Hönes J, Müller P, Surridge N: The technology behind glucose meters: test strips. Diabetes Technol Ther 2008;10:10-26.

3. Wang J: Electrochemical glucose biosensors. Chem Rev 2008;108:814-825.

4. Yoo EH, Lee SY: Glucose biosensors: an overview of use in clinical practice. Sensors (Basel) 2010;10:4558-4576.

5. Chaubey A, Malhotra BD: Mediated biosensors. Biosens Bioelectron 2002;17:441-456.

6. Ferri S, Kojima K, Sode K: Review of glucose oxidases and glucose dehydrogenases: a bird's eye view of glucose sensing enzymes. J Diabetes Sci Technol 2011;5:1068-1076.

7. Kost GJ, Vu HT, Lee JH, Bourgeois P, Kiechle FL, Martin C, Miller SS, Okorodudu AO, Podczasy JJ, Webster R, Whitlow $\mathrm{KJ}$ : Multicenter study of oxygen-insensitive handheld glucose point-of-care testing in critical care/hospital/ambulatory patients in the United States and Canada. Crit Care Med 1998;26:581-590.

8. Tang Z, Louie RF, Lee JH, Lee DM, Miller EE, Kost GJ: Oxygen effects on glucose meter measurements with glucose dehydrogenase- and oxidase-based test strips for point-ofcare testing. Crit Care Med 2001;29:1062-1070.

9. Kurahashi K, Maruta H, Usuda Y, Ohtsuka M: Influence of blood sample oxygen tension on blood glucose concentration measured using an enzyme-electrode method. Crit Care Med 1997;25:231-235.

10. Chun TY, Hirose M, Sawa T, Harada M, Hosokawa T, Tanaka $\mathrm{Y}$, Miyazaki M: The effect of the partial pressure of oxygen on blood glucose concentration examined using glucose oxidase with ferricyan ion. Anesth Analg 1994;79:993-997.

11. Louie RF, Tang Z, Sutton DV, Lee JH, Kost GJ: Point-of-care glucose testing: effects of critical care variables, influence of reference instruments, and a modular glucose meter design. Arch Pathol Lab Med 2000;124:257-266.

12. Higgins C: Capillary blood gases: to arterialize or not. MLO Med Lab Obs 2008;40:42-47.

13. Fajac I, Texereau J, Rivoal V, Dessanges JF, Dinh-Xuan AT, Dall'Ava-Santucci J: Blood gas measurement during exercise: a comparative study between arterialized earlobe sampling and direct arterial puncture in adults. Eur Respir J 1998;11:712-715

14. Ak A, Ogun CO, Bayir A, Kayis SA, Koylu R: Prediction of arterial blood gas values from venous blood gas values in patients with acute exacerbation of chronic obstructive pulmonary disease. Tohoku J Exp Med 2006;210:285-290.

15. Mays EE: An arterial blood gas diagram for clinical use. Chest 1973;63:793-800.

16. O'Connor TM, Barry PJ, Jahangir A, Finn C, Buckley BM, ElGammal A: Comparison of arterial and venous blood gases and the effects of analysis delay and air contamination on arterial samples in patients with chronic obstructive pulmonary disease and healthy controls. Respiration 2011;81: $18-25$.

17. Fischer R: High altitude and pulmonary diseases. Dtsche Z Sportmedizin 2000;51:412-417.

18. Garcia RF, Borderias CL, Casanova MC, Celli BR, Escarrabill SJ, Gonzalez MN, Roca TJ, Uresandi RF: [Air travel and respiratory diseases]. Arch Bronconeumol 2007;43:101125.

19. Coker RK, Partridge MR: What happens to patients with respiratory disease when they fly? Thorax 2004;59:919-920.

20. Cakar N, Tuorul M, Demirarslan A, Nahum A, Adams A, Akyncy O, Esen F, Telci L: Time required for partial pressure of arterial oxygen equilibration during mechanical ventilation after a step change in fractional inspired oxygen concentration. Intensive Care Med 2001;27:655-659.

21. Tang Z, Louie RF, Payes M, Chang KC, Kost GJ: Oxygen effects on glucose measurements with a reference analyzer and three handheld meters. Diabetes Technol Ther 2000;2:349-362.

22. Mahoney JJ, Ellison JM, Cabezudo JI, Cariski AT: Protocol errors may lead to incorrect conclusions. Diabetes Technol Ther 2011;13:171.

23. Oberg D, Ostenson CG: Performance of glucose dehydrogenase- and glucose oxidase-based blood glucose meters at high altitude and low temperature. Diabetes Care 2005;28:1261.

24. Pecchio O, Maule S, Migliardi M, Trento M, Veglio M: Effects of exposure at an altitude of 3,000 $\mathrm{m}$ on performance of glucose meters. Diabetes Care 2000;23:129-131.

25. Fink KS, Christensen DB, Ellsworth A: Effect of high altitude on blood glucose meter performance. Diabetes Technol Ther 2002;4:627-635. 
26. deMol P, Krabbe HG, de Vries ST, Fokkert MJ, Dikkeschei BD, Rienks R, Bilo KM, Bilo HJ: Accuracy of handheld blood glucose meters at high altitude. PLoS One 2010;5: e15485.

27. Olateju T, Begley J, Flanagan D, Kerr D: Effects of simulated altitude on blood glucose meter performance: implications for in-flight blood glucose monitoring. J Diabetes Sci Technol 2012;6:867-874.

28. International Organization for Standardization: In Vitro Diagnostic Test Systems-Requirements for Blood-Glucose Monitoring Systems for Self-Testing in Managing Diabetes
Mellitus. ISO 15197:2013. Geneva: International Organization for Standardization, 2013.

Address correspondence to: Christina Schmid, PhD

Institut für Diabetes-Technologie Forschungs- und Entwicklungsgesellschaft $\mathrm{mbH}$ an der Universität Ulm

Helmholtzstrasse 20 89081 Ulm, Germany

E-mail: christina.schmid@uni-ulm.de 